\title{
Investigation into Magnetic Control of Hard-Switching DC-DC Converters
}

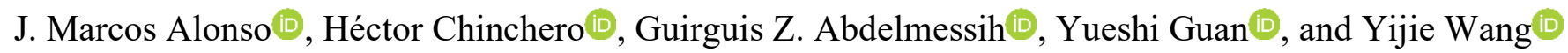

\begin{abstract}
In this paper an investigation into magnetic control (MC) of hard-switching (HS) DC-DC converters is carried out. The proposed control method is based on the modulation of the effective filter inductance of the converter when operating in discontinuous conduction mode (DCM). It is well known that the output characteristic of a HS DC-DC converter operating in DCM is dependent on the effective inductance of the output filter. This way, by using a variable inductance the output of the converter can be controlled. The proposed control method can be applied to any converter topology, namely buck, boost, buckboost, flyback, forward, and so on. In this paper, the operation of the buck converter with MC is investigated in detail as a case study. This work proves that the proposed control method can be effectively used to control DC-DC converters on its own or by combination with other control parameters as duty cycle and/or frequency. An experimental prototype has been built to test the proposed control method and modeling process and to demonstrate its feasibility and possibilities.
\end{abstract}

Keywords - magnetic devices, variable inductors, DC-DC converters, magnetic control, DCM operation.

\section{INTRODUCTION}

Switching DC-DC converters are used in a vast range of applications, including battery chargers, LED drivers, uninterruptible power supplies (UPS), housekeeping power supplies, point-of-load converters, etc. For low power applications, hard-switching (HS) DC-DC converters are the preferred option because of their simplicity, good efficiency, reliability and low component count. The most common and well-known topologies for low power applications are the buck, boost, buck-boost, flyback and forward converters. These converters can be controlled in a great variety of control methods, like voltage mode control and current-programmed control, which are primarily used. However, control methods proposed until now are based on directly or indirectly changing the switch duty cycle and/or switching frequency [1]. Magnetic regulators have been presented in previous literature as a means to improve the operation of power converters [2]-[23]. They have successfully been employed in controlling resonant inverters for electronic ballast [4]-[9], DC-DC converters [10]-[14], power converters for photovoltaic (PV) applications [15], power factor correction (PFC) converters [16][17], LED drivers [18]-[20], smart-grid applications [21], and battery charging [22][23].

J. Marcos Alonso, Héctor Chinchero and Guirguis Z. Abdelmessih are with the Department of Electrical Engineering, University of Oviedo, 33204 Gijon, Spain (e-mail: marcos@uniovi.es; UO248474@uniovi.es; UO242517@uniovi.es).

Yueshi Guan and Yijie Wang are with Harbin Institute of Technology, No. 92, Xidazhi Street, Harbin, 150001, China. (email: hitguanyueshi@163.com; wangyijie@hit.edu.cn).
This paper looks into the possibility of controlling HS DCDC converters based on the modulation of the inductance used in the converter output filter. The goal of this work is the evaluation of the possibilities of this control method, which could be used in some niche applications on its own or by combination with duty cycle and/or frequency control. Some advantages of the proposed magnetic control can be identified as follows: i) constant frequency operation, ii) constant duty cycle operation, iii) implementation of multi-output converters with a reduced number of power switches, iv) additional control parameter for different control strategies, and v) simple dynamics, easy to stabilize in closed loop.

In order to introduce the proposed control method, which will be referred to as magnetic control (MC) of DC-DC converters, Fig. 1 illustrates a buck converter and its operating waveforms when it is working under continuous conduction mode (CCM) and discontinuous conduction mode (DCM).

Fig. 1a shows the current waveform through the inductor when the converter operates in CCM for two different values of the inductance $L_{1}$ and $L_{2}$ higher than $L_{1}$. As can be seen, when operating in CCM any change of the inductance will produce just a change on the inductor current ripple, while the average output current and voltage will keep the same. Therefore, it is not possible to use the inductance as control parameter for the output voltage and current when the converter operates in CCM. Nevertheless, in CCM the change in the inductance will produce a change on the dynamic response of the converter. The lower the inductance, the quicker the dynamic response of the converter. Thus, in CCM $\mathrm{MC}$ can be used to act upon the dynamic response of the converter to be adapted to the load or input voltage changes. This idea has previously been investigated in [12].

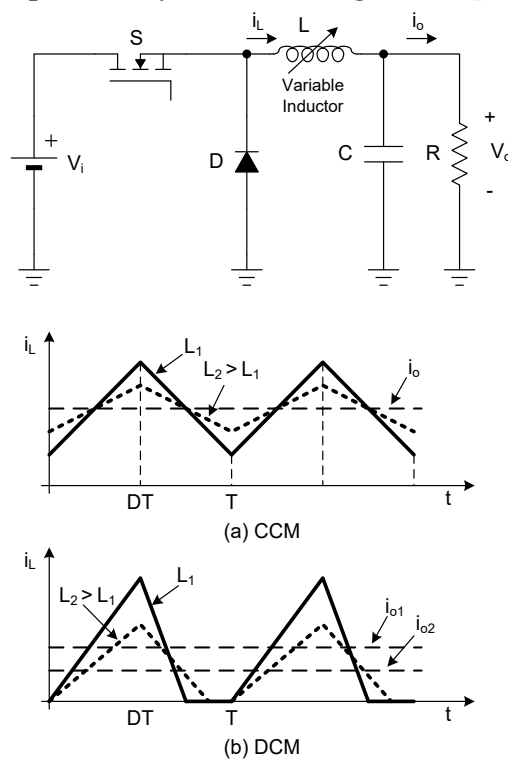

Fig. 1. Buck converter and operating waveforms under MC. 
On the other hand, Fig. 1b shows the inductor current waveforms when the converter is operating in DCM. In this case, the inductor has a direct effect on the average output current and voltage. As the value of the inductance increases, the average output current will decrease and so will do the average output voltage.

It is also possible to observe in Fig. $1 \mathrm{~b}$ that as long as the inductance is increasing, the converter operation is approaching to CCM operation. Therefore, for a given switch duty cycle and switching frequency, there will be a maximum value of the inductance beyond which the buck converter will enter in CCM mode, and the output voltage and current will be fixed to that of the CCM characteristic, which as it is well known will depend exclusively on the switch duty cycle in the ideal case.

In the following, Section II presents the MC of DC-DC converters operating in DCM. Section III focuses on the study of the buck converter with MC, which has been selected as a case study to investigate the proposed control method. Section IV presents the implementation of a laboratory prototype. Section V shows the experimental verification. Finally, Section VI presents the conclusions that can be extracted from this work.

\section{MAGNETIC CONTROL OF DC-DC CONVERTERS UNDER DCM OPERATION}

\section{A. DC-DC DCM Converters with Magnetic Control}

Fig. 1a and Fig. 2 show the schematic diagrams of the five basic DC-DC converters operating under MC, namely buck, boost, buck-boost, flyback and forward converters.

DC-DC converters have extensively been studied in CCM and DCM operation. From the studies presented in [1], it is possible to obtain the output characteristics of the different converters operating in DCM under MC. For this purpose, the normalized inductance $L_{n}$ of the converter is defined as follows:

$$
L_{n}=\frac{L}{R / 2 f}
$$

where $L$ is the inductance of the converter, and in the case of the flyback converter is the inductance seen from the primary side of the coupled inductors, $R$ represents the load resistance and $f$ is the converter switching frequency. Thus, Table I provides the output characteristic of the five converters and the condition of DCM operation from the point of view of the value of the controllable normalized inductance. In the equations of Table I, $D$ represents the switch duty cycle, and $n=N_{s} / N_{p}$ is the turn ratio of the flyback coupled inductors or the forward transformer, $N_{s}$ and $N_{p}$ being the turn numbers of secondary and primary windings respectively.

As can be seen from Table I, the voltage gain of the converters in DCM is a direct function of the inductance. This makes it possible to control the converter output voltage or current by means of inductance variation, i.e. by MC.

In order to provide a clearer insight on the static behavior of the different converters under $\mathrm{MC}$, the output characteristics of Table I have been plotted in Fig. 3 and Fig. 4. Fig. 3 shows the output characteristic of the buck, boost and buck-boost converter. Fig. 4 illustrates the output characteristics of the flyback converter for a turn ratio $n=0.5$ and of the forward converter for a turn ratio $n=2$. As can be seen, in all characteristics there is a range corresponding to the DCM operation of the converter within which it is possible to control the output by changing the converter inductance. On the other hand, in the range corresponding to $\mathrm{CCM}$ operation, the voltage gain will remain constant; the change of the inductance has no effect on the average value of the output, affecting only to the converter filter cut-off frequency and thus to the current and voltage ripple. For the flyback and forward converters the effect of the turn ratio $n$ is to increase the DCM range of operation for the same voltage gain range, which is good because it is a manner of extending the range of output regulation of the converter.

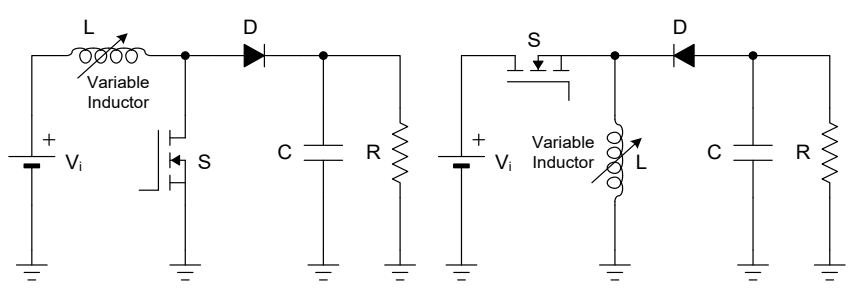

(a)

(b)

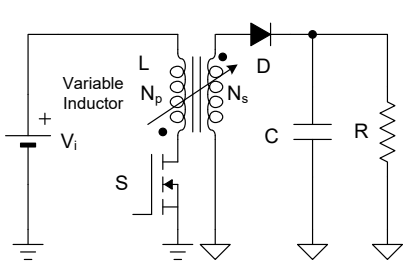

(c)

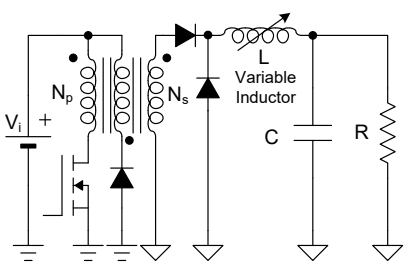

(d)
Fig. 2. DC-DC converters with MC: (a) boost, (b) buck-boost, (c) flyback and (d) forward.

TABLE I. CHARACTERISTICS OF DCM DC-DC CONVERTERS WITH MC.

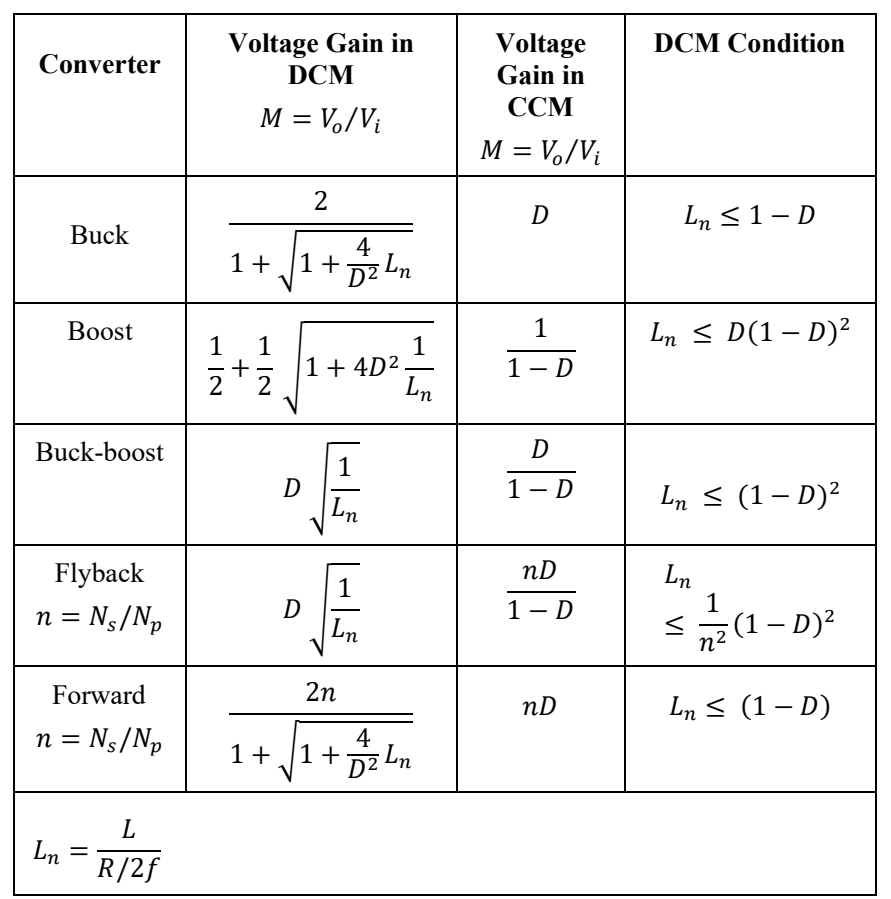




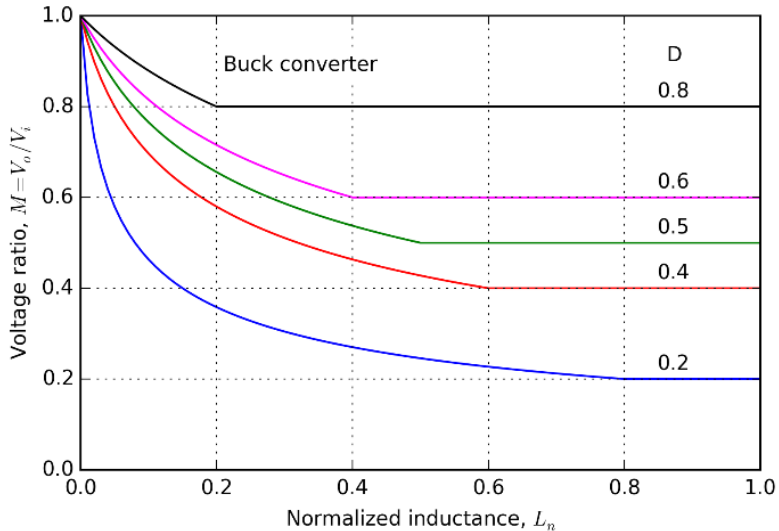

(a)

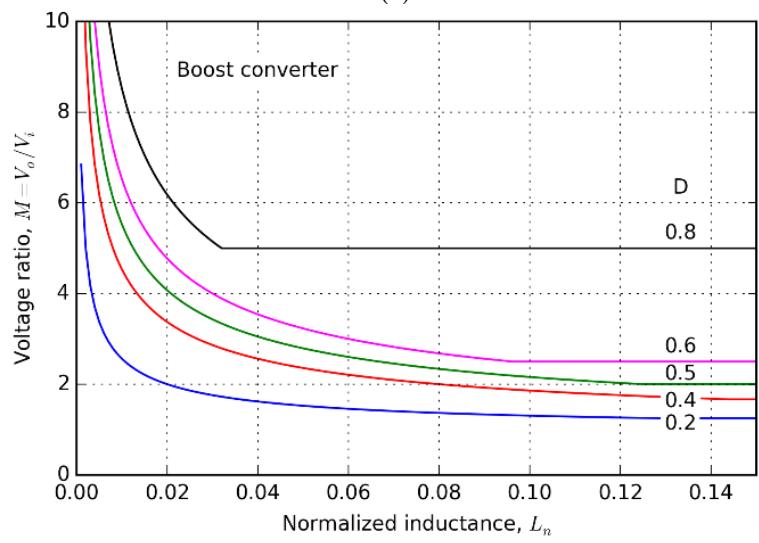

(b)

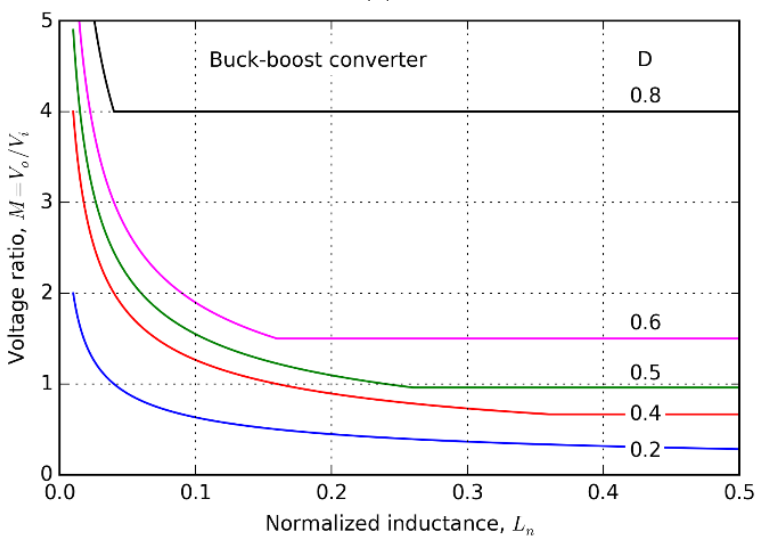

(c)

Fig. 3. Voltage ratio characteristics of the three basic non-isolated DC-DC converters with MC: (a) buck converter, (b) boost converter, and (c) buck-boost converter.

\section{B. Implementation of Variable Inductors}

Variable inductors (VI) have been studied in previous literature [24]-[27]. These devices are capable of providing an inductance that can be controlled by a DC current injected in one or more auxiliary windings. The DC current generates a biasing magnetic flux that changes the DC operating point of the AC magnetic flux inside the core. This way, by moving the DC operating point along the B-H curve of the material close to the saturation knee, the permeability is changed, thus providing a variation of the effective inductance of the AC winding. Fig. 5 shows the scheme of two common VI; the double-E VI and the quad-U VI. These structures have previously been studied in [24]-[27], where it can be found more information on how to analyze, design and simulate these VI structures.

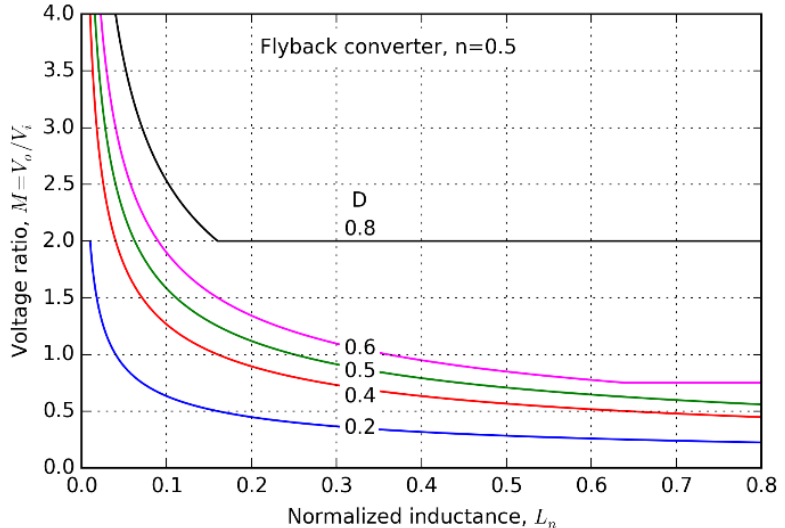

(a)

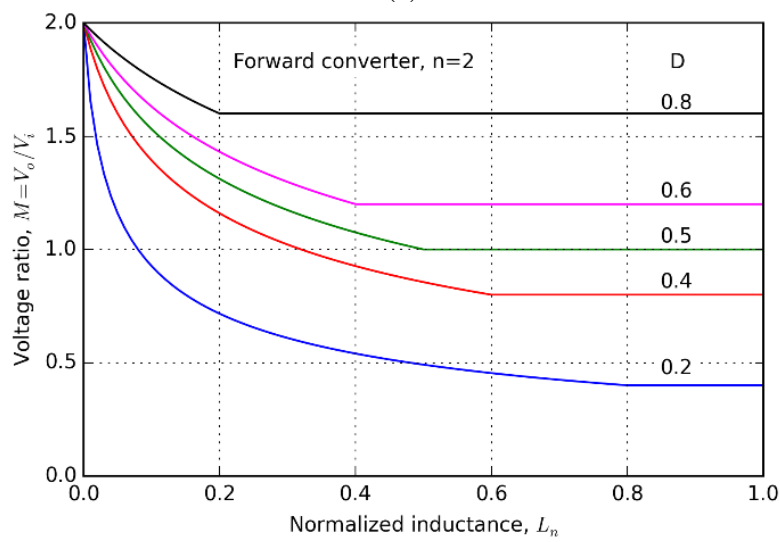

(b)

Fig. 4. Voltage ratio characteristics of the two basic isolated DC-DC converters with MC: (a) flyback converter, and (b) forward converter.

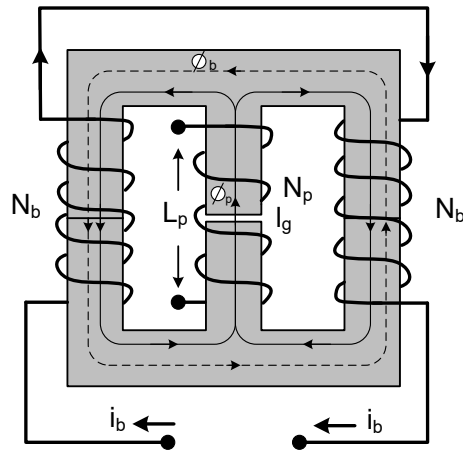

(a)

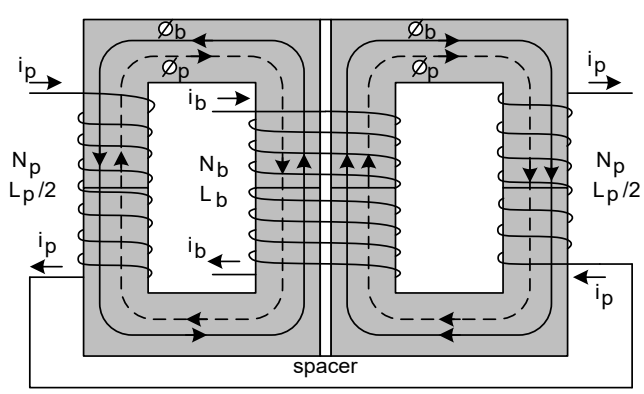

(b)

Fig. 5. Schematic of two VI structures: (a) double-E VI, (b) quad-U VI. 


\section{CASE StUdy: Buck CONVERTER With Magnetic CONTROL}

In order to evaluate the possibilities of applying $\mathrm{MC}$ to DCM-operated DC-DC converters, a case study for the buck converter will be carried out in this section.

\section{A. Static Analysis of the Buck Converter with Magnetic Control}

The static characteristics of the buck converter operating in DCM with $\mathrm{MC}$ can be obtained from the normalized characteristics shown in Table I. By substituting the normalized inductance given by (1), the following expression can be obtained for the converter voltage gain $M$ :

$$
\begin{array}{ccc}
M=\frac{V_{o}}{V_{i}}=\frac{2}{1+\sqrt{1+\frac{8 f L}{D^{2} R}}} & \text { if } L \leq(1-D) \frac{R}{2 f} \\
M=\frac{V_{o}}{V_{i}}=D & \text { if } L \geq(1-D) \frac{R}{2 f}
\end{array}
$$

As an example, Fig. 6 shows the voltage gain characteristics of the buck converter for a particular case with duty cycle $D=$ 0.4 , switching frequency $f=100 \mathrm{kHz}$ and inductance up to $25 \mu \mathrm{H}$, which have been obtained by plotting (2). As can be seen, for a given load resistance, DCM operation is achieved for the lower values of the converter inductance. When a critical inductance value is reached, the converter enters in $\mathrm{CCM}$ operation and the voltage gain becomes constant and equal to the converter duty cycle, $D$. Voltage regulation can only be achieved in DCM operation, while in CCM mode any change of the inductance will affect only to the current and voltage ripple and to the converters dynamics but not to the average output voltage.

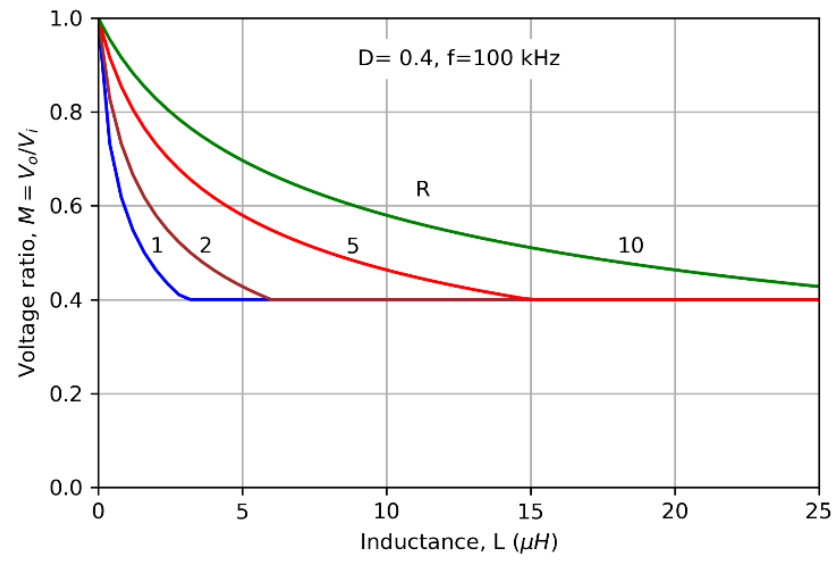

Fig. 6. Voltage gain of a buck converter as a function of the converter inductance for different load resistances.

\section{B. Proposed Control Scheme}

The proposed control scheme of the buck converter operating in DCM mode with MC is illustrated in Fig. 7. As can be seen, the circuit is quite simple. The output voltage is measured by a voltage divider and fed into a lag-lead compensator, which drives the bipolar transistor Q in order to generate the required bias current $i_{b}$ for the variable inductor. For a proper design of the compensator parameters, the dynamic model of the buck converter with MC needs to be obtained. This analysis will be presented in the next section.

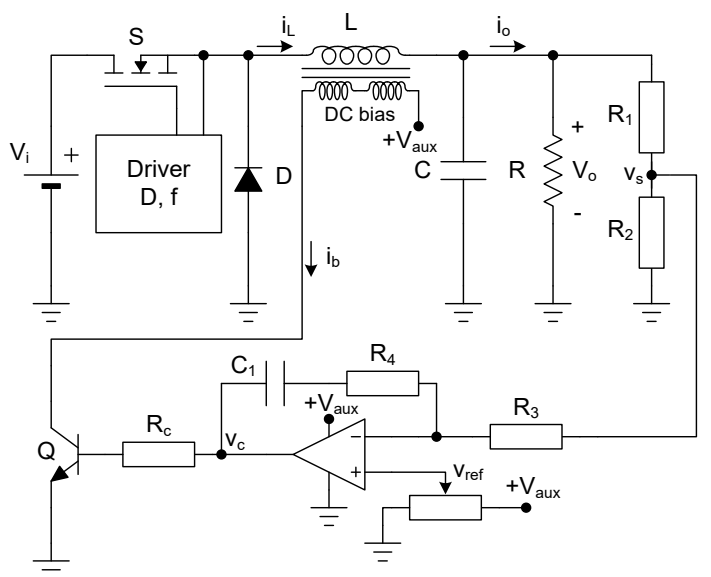

Fig. 7. Proposed control scheme of the DCM operated buck converter with MC.

\section{Dynamic Model of the Buck Converter with Magnetic Control}

In this section, the basic dynamic analysis of the buck converter with MC will be presented. With reference to the control scheme previously presented in Fig. 7, the objective of the analysis is to obtain the transfer function $G_{o l}(s)$ that relates the inductance perturbation $l(s)$ with the output voltage perturbation $v_{o}(s)$, this is:

$$
G_{o l}(s)=\frac{v_{o}(s)}{l(s)}
$$

Fig. 8 shows the equivalent circuits of the buck converter operating in DCM in the averaged time domain, Fig. 8a, and in the Laplace variable domain, Fig. $8 b$. The effect of the series resistance of the filter capacitor have been neglected for simplicity assuming that a film capacitor with very low series resistance will be used; nevertheless, it could easily be taken into account. The inductor average current of the buck converter in DCM mode can be calculated as follows:

$$
\left\langle i_{L}\right\rangle=\frac{D^{2} V_{i}}{2 f}\left(\frac{V_{i}}{V_{o}}-1\right) \frac{1}{L}
$$

By taking partial derivative with respect to $L$ and using the Laplace transform, the following relationship is obtained between the inductor current and inductor perturbations:

where

$$
i_{L}(s)=k_{i l} l(s)
$$

$$
k_{i l}=-\frac{D^{2} V_{i}}{2 f}\left(\frac{V_{i}}{V_{o}}-1\right) \frac{1}{L^{2}}
$$

Now, solving the circuit shown in Fig. $8 \mathrm{~b}$ for the output voltage, the buck converter dynamics between the output voltage and inductor can be obtained, as follows:

$$
G_{o l}(s)=\frac{v_{o}(s)}{l(s)}=k_{o l} \frac{1}{1+s / \omega_{p}}
$$

where

$$
\begin{gathered}
k_{o l}=k_{i l} R \\
\omega_{p}=\frac{1}{R C}
\end{gathered}
$$

As stated in [20], it is a good approximation to neglect the dynamics between VI bias flux perturbations $B_{b}(s)$ and VI 
inductance perturbations $l(s)$ because this dynamics will be of a higher order of magnitude in comparison with the other dynamics of the VI. Therefore, the following expression can be written:

$$
l(s) \approx k_{l b} B_{b}(s)
$$

where $k_{l b}$ is the proportionality constant that relates inductance and bias flux perturbations. The procedure to derive this constant is presented in Appendix I.

Also, the bias flux and bias current $i_{b}(s)$ perturbation can be related by the following expression:

$$
B_{b}(s)=\frac{L_{b \_} e f f}{2 N_{b} A_{b}} i_{b}(s)
$$

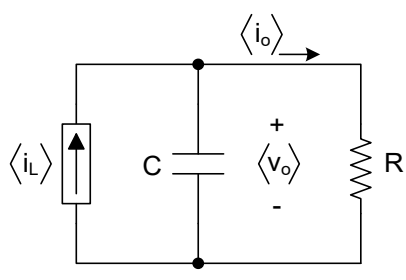

(a)

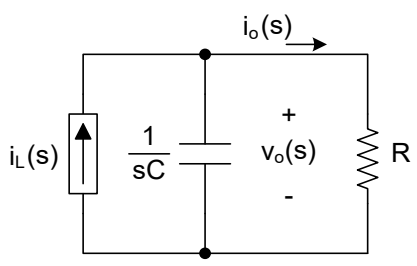

(b)
Fig. 8. Equivalent circuits of the buck converter with MC: (a) averaged time domain, and (b) Laplace variable domain.

where $L_{b_{-} e f f}, N_{b}$ and $A_{b}$ are the effective inductance [20], turn number and effective section of the auxiliary bias winding, respectively.

Note that in (11) the factor 2 before $N_{b}$ is necessary because the total bias inductance is given by two bias windings, each one with a number of turns equal to $N_{b}$.

Using (11) in (10), a direct relationship between inductance and bias current perturbations can be obtained:

$$
l(s) \approx k_{l i} i_{b}(s)
$$

where:

$$
k_{l i}=\frac{k_{l b} L_{b_{-} e f f}}{2 N_{b} A_{b}}
$$

It must be noted that the constant $k_{l i}$ corresponds to the slope of the characteristic of inductance versus bias current of the VI at the given operating point, which can be obtained theoretically following the process shown in [24][27].

With regard to the dynamics between the compensator output signal $v_{c}$ and the bias winding current $i_{b}$, it has already been studied in [20]. It can be expressed as follows:

$$
G_{b c}(s)=\frac{i_{b}(s)}{v_{c}(s)}=\frac{k_{b c}}{1+s / \omega_{c}}
$$

where

$$
\begin{gathered}
k_{b c}=\frac{h_{f e}}{R_{c}+h_{i e}} \cdot \frac{1}{1+h_{o e} R_{b}} \\
\omega_{c}=\frac{h_{o e}^{-1}+R_{b}}{L_{b \_e f f}}
\end{gathered}
$$

where $h_{i e}, h_{f e}$ and $h_{o e}$ are the $h$ parameters of the small-signal model of the bipolar transistor used in the bias winding, namely input impedance, forward current gain and output admittance respectively. These parameters can be obtained from the transistor datasheet if available. Other option is to extract the parameters from its SPICE model by computer simulation. The latter has been the option used in this work.
Fig. 9 shows the block diagram of the derived dynamic model of the buck converter operating with MC. The following transfer function can be defined to represent the dynamic behavior from the control voltage $v_{c}$ to the output voltage $v_{o}$ :

$$
G_{o}(s)=\frac{v_{o}(s)}{v_{c}(s)}=k_{l i} G_{b c}(s) G_{o l}(s)
$$

which corresponds to a transfer function with two poles given by $\omega_{p}$ and $\omega_{c}$ in (9) and (16) respectively.

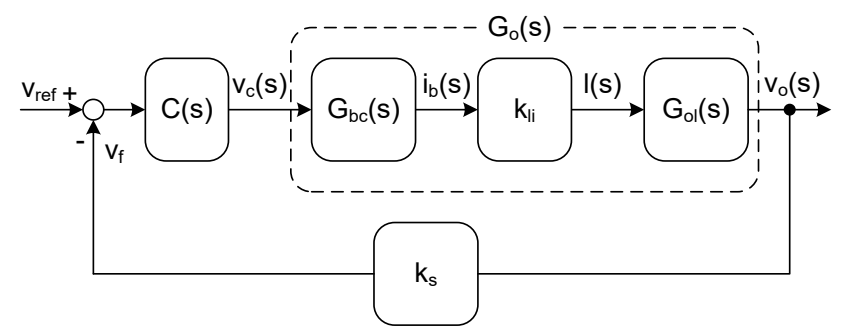

Fig. 9. Block diagram of the dynamic model of the buck converter with MC.

The gain of the feedback network is given by $R_{1}$ and $R_{2}$ in Fig. 7, as follows:

$$
k_{s}=\frac{R_{2}}{R_{1}+R_{2}}
$$

\section{IMPLEMENTED PROTOTYPE}

As an example of implementation, a buck converter operating at a switching frequency of $100 \mathrm{kHz}$ and with a duty cycle of 0.4 (on time, $t_{o n}=4 \mu \mathrm{s}$ ) will be presented and studied in this section. According to the characteristics of Fig. 6, a VI ranging from $5 \mu H$ to $20 \mu H$ has been implemented with the parameters shown in Table II. Fig. 10 shows the characteristic of inductance versus bias current of the implemented VI.

The buck converter has been supplied with $10 \mathrm{~V}$ input voltage and nominal load resistance of $5 \Omega$. The output filter capacitance is $33 \mu \mathrm{F}$, implemented with a film capacitor so that its series resistance can be neglected. Table III summarizes the parameters of the implemented prototype. The $h$ parameters of the BD139 bipolar transistor used in the bias circuit have been obtained from the SPICE model of the transistor by simulation under LTspice. Appendix II shows the two LTspice circuits that were used for this purpose.

Based on the analysis presented in Section II.C, the dynamic response of the converter with $\mathrm{MC}$ has been obtained. Fig. 11 shows this response, corresponding to the bode diagram of amplitude and phase of output voltage $v_{o}(s)$ over control voltage $v_{c}(s)$, which has been designated as $G_{o}(s)$ in Section II.C. Appendix III shows a WinPython 3.7.7 script that can be used to generate this response and to calculate the other transfer functions and poles of the system. From this theoretical analysis, the pole corresponding to the buck output filter as given by (9) is obtained at $964 \mathrm{~Hz}$, while the pole due to the VI response, given by (16), appears at $35.2 \mathrm{kHz}$. The $\mathrm{DC}$ gain of the system is $8.96 \mathrm{~dB}$. 
TABLE II. PARAMETERS OF THE IMPLEMENTED VI.

\begin{tabular}{|l|l|}
\hline Parameter & Type/Value \\
\hline Structure & Double E \\
\hline Core & EFD25/13/9, N87 \\
\hline Main winding & $\mathrm{N}=12,66 \times 0.08 \mathrm{~mm}$ (litz) \\
\hline Central arm cross-sectional area & $\mathrm{A}_{\mathrm{c}}=59.3 \mathrm{~mm}^{2}$ \\
\hline Central arm length & $1_{\mathrm{c}}=24.4 \mathrm{~mm}$ \\
\hline Middle arm gap & $1_{\mathrm{gc}}=0.6 \mathrm{~mm}$ \\
\hline Lateral arms gap & $1_{\mathrm{ge}}=0 \mathrm{~mm}$ \\
\hline Bias windings & $2 \times \mathrm{N}_{\mathrm{b}}=65,1 \times 0.2 \mathrm{~mm}$ \\
\hline Outer arms cross-sectional area & $\mathrm{A}_{\mathrm{e}}=28.7 \mathrm{~mm}{ }^{2}$ \\
\hline Outer arms length & $1_{\mathrm{e}}=43.6 \mathrm{~mm}$ \\
\hline Main inductance range & $5 \mu \mathrm{H}-20 \mu \mathrm{H}$ \\
\hline $\begin{array}{l}\text { Bias winding effective series } \\
\text { inductance and resistance }\end{array}$ & $1.2 \mathrm{mH} / 6.2 \Omega @ 100 \mathrm{~Hz}$ \\
\hline
\end{tabular}

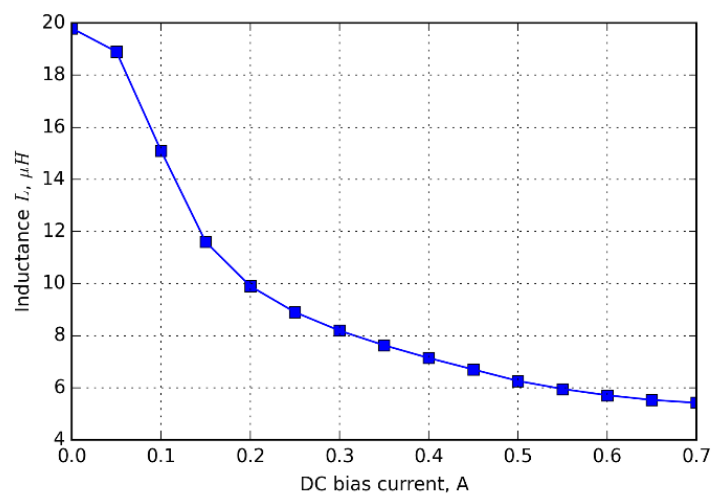

Fig. 10. Measured characteristic of inductance versus bias current of the implemented VI.

TABLE III. PARAMETERS OF THE IMPLEMENTED BUCK CONVERTER WITH MC.

\begin{tabular}{|l|l|}
\hline Parameter & Type/Value \\
\hline Input voltage & $10 \mathrm{~V}$ \\
\hline Output voltage & $5 \mathrm{~V}$ \\
\hline Duty cycle & 0.4 \\
\hline Switching frequency & $100 \mathrm{kHz}$ \\
\hline Inductor & $5 \mu \mathrm{H}-20 \mu \mathrm{H}$ \\
\hline Capacitor & $33 \mu \mathrm{F}$ \\
\hline Nominal load resistance & $5 \Omega$ \\
\hline Power switch & $\mathrm{IRFZ} 48$ \\
\hline Diode & $11 \mathrm{DQ} 10$ \\
\hline $\begin{array}{l}\text { Bias winding transistor model } \\
\text { parameters }\end{array}$ & $\mathrm{BD} 139 / h_{f e}=43.8, h_{i e}=$ \\
\hline $\begin{array}{l}\text { Bias winding transistor base } \\
\text { resistance }\end{array}$ & $28.2 \Omega, h_{o e}=0.0079 \Omega^{-1}$ \\
\hline Voltage sensing resistances & $\mathrm{R}_{\mathrm{c}}=100 \Omega$ \\
\hline
\end{tabular}
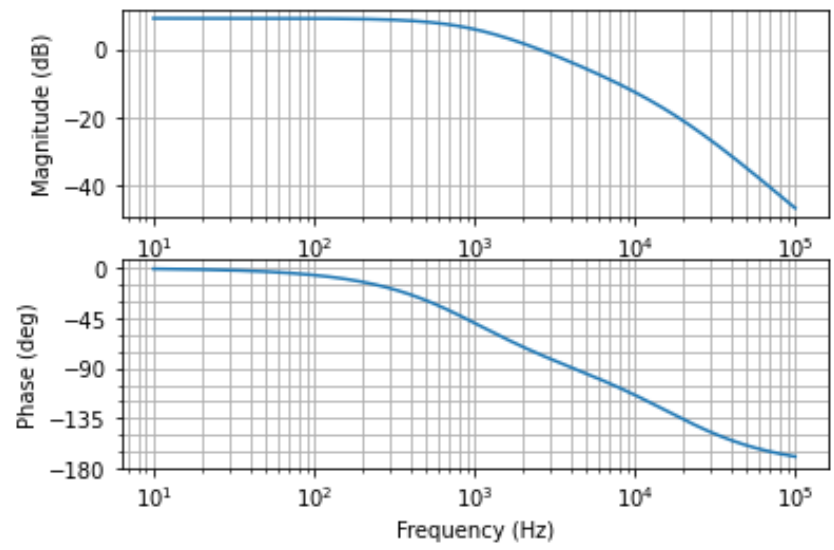

Fig. 11. Theoretical bode diagram of the converter in open loop, corresponding to the transfer function $G_{o}(s)$ in the block diagram of Fig. 9.

\section{EXPERIMENTAL VERIFICATION}

Firstly, the characteristic of output voltage $v_{o}$ versus control voltage $v_{c}$ has been measured at the laboratory operating with duty cycle of 0.4 and load resistance of $5 \Omega$. Fig. 12 shows the obtained result. The squares show the experimental measurement, while the dashed line shows an approximation obtained by exponential regression. As can be seen, the output voltage can be controlled within a reasonably wide range by means of the control voltage $v_{c}$, which changes the effective value of the converter inductance.

As previously explained, the slope of the output control curve shown in Fig. 12 can be used to obtain the total DC gain of the converter control function $G_{o}(s)$. For example, around the nominal operating point of $5 \mathrm{~V}$ at the output, the slope can be approximated to $3.61(11.1 \mathrm{~dB})$.

Fig. 13 shows the buck converter filter input voltage and VI current in two different situations of output voltage and current. Fig. 13a corresponds to an output voltage and current of $5 \mathrm{~V}$ and $1 \mathrm{~A}$ respectively. As can be seen, the converter is operating at the DCM-CCM mode. Fig. 13b shows the waveforms for an output voltage and current of $5.5 \mathrm{~V}$ and 1.1 A. As can be seen, in this case the converter is clearly operating in DCM mode. This is because to increase the output voltage, the VI inductance must be decreased, what according to the characteristics in Fig. 3a and Fig. 6, forces the operation to go further into DCM mode.

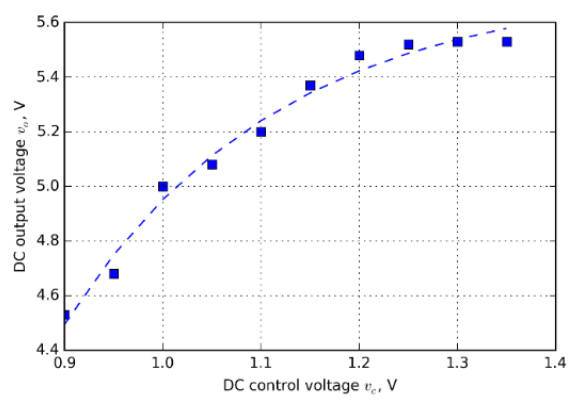

Fig. 12. Characteristic of output voltage versus control voltage of the buck converter with MC. Squares: experimental measurement; dashed line: approximation by exponential curve fitting. 


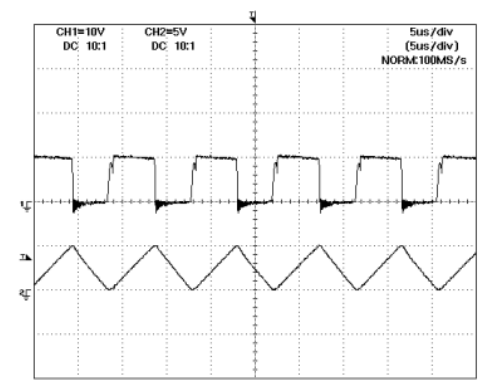

(a)

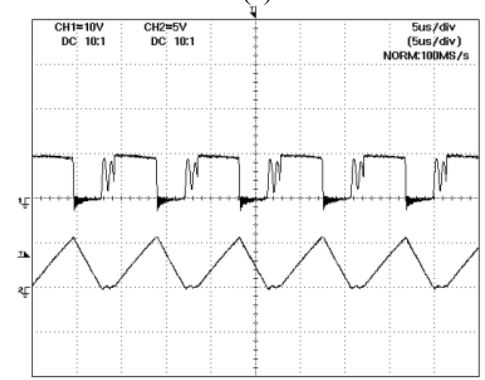

(b)

Fig. 13. Buck filter input voltage and VI current in two different situations: (a) $V_{o}=5 \mathrm{~V}, I_{o}=1 \mathrm{~A}$; (b) $V_{o}=5.5 \mathrm{~V}, I_{o}=1.1 \mathrm{~A}$. Scales: $10 \mathrm{~V} / \mathrm{div}$, $1 \mathrm{~A} / \mathrm{div}, 5 \mu \mathrm{s} / \mathrm{div}$.

The second test performed on the prototype was to measure the system dynamics by acquiring the bode diagram of the system transfer function $G_{o}(s)$. An Omicron Bode 100 has been used for this operation. Fig. 14 shows the obtained results. As can be seen, the response matches with quite good accuracy the theoretical response shown previously in Fig. 11, which validates the developed dynamic model.

In order to test the system regulation in closed loop, a laglead compensator as the one illustrated in Fig. 7 has been designed. Table IV shows the parameters of the implemented compensator.
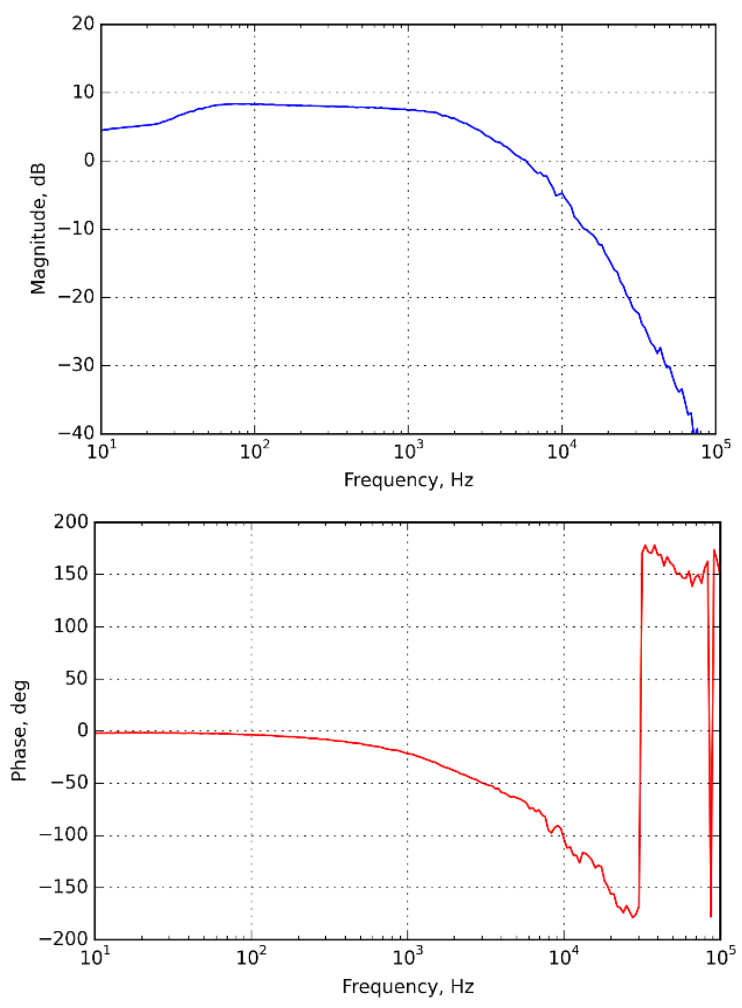

Fig. 14. Experimental response of the control transfer function $G_{o}(s)$ corresponding to the implemented buck converter with MC.
TABLE IV. PARAMETERS OF THE IMPLEMENTED LAG-LEAD COMPENSATOR.

\begin{tabular}{|l|l|}
\hline Parameter & Type/Value \\
\hline High frequency gain & $0 \mathrm{~dB}$ \\
\hline Zero's frequency & $1 \mathrm{kHz}$ \\
\hline Operational amplifier & $\mathrm{LM} 358$ \\
\hline Resistances $R_{3}, R_{4}$ & $16 k \Omega$ \\
\hline Capacitance $C_{1}$ & $10 \mathrm{nF}$ \\
\hline
\end{tabular}

Fig. 15 shows the experimental loop gain magnitude and phase of the buck converter with MC when using the compensator shown in Table IV. The measurement was taken using the voltage injection method, with an injection transformer B-WIT 100 from Omicron. As can be seen, the loop gain response is in accordance with the theoretical analysis. The system is well stabilized with a phase margin of around 110 degrees and a gain margin of around $40 \mathrm{~dB}$.
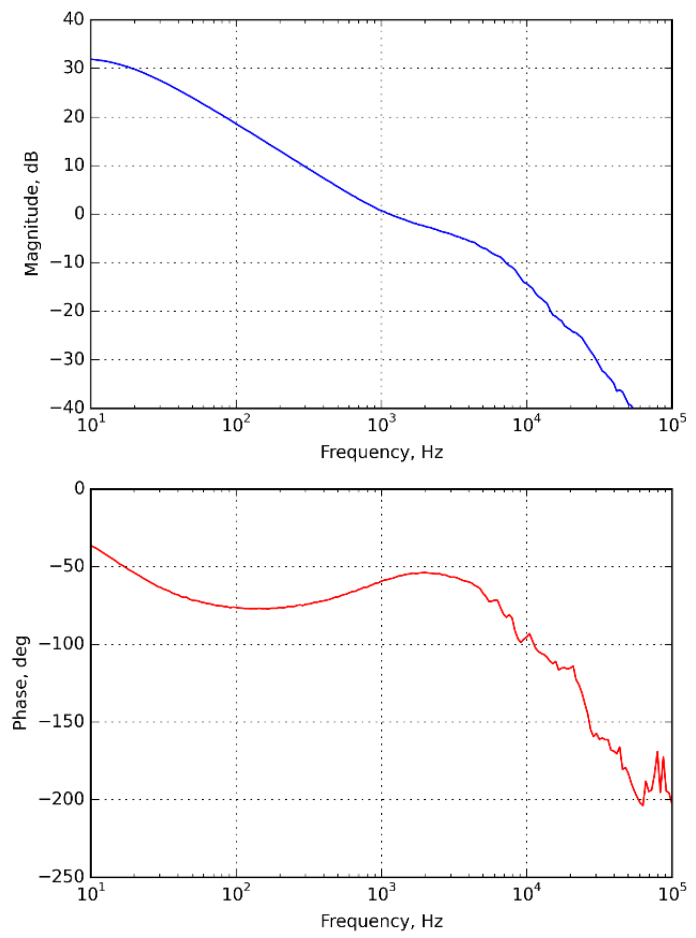

Fig. 15. Experimental loop gain and phase of the buck converter operating with a lag-lead compensator and MC.

Fig. 16 shows experimental responses of the buck converter operating in closed loop with the proposed MC. Fig. 16a shows the output voltage response for a load step between $5 \Omega$ and $10 \Omega$. The output voltage response is in accordance with the expected one since it corresponds to a first order response with a settling time around $500 \mu$ s. Fig. $16 \mathrm{~b}$ shows the output voltage response for an input voltage change between $8 \mathrm{~V}$ and 11 V. A first order response with a settling time around 500 $\mu \mathrm{s}$ is also obtained, which is in accordance with the system closed-loop design.

Table V and VI shows the experimental measurements corresponding to the load regulation (Table $\mathrm{V})$ and line regulation (Table VI). The values of the control signal $v_{c}$ generated by the compensator and of the dc current through the bias winding $i_{b}$ are also provided to show the operation of the closed-loop regulation. As can be seen in both tables, even though the control range is not very wide for this particular 
design, the output voltage is well regulated for both load and line changes, thus proving the feasibility of the proposed control methodology.

\section{CONCLUSIONS}

The magnetic control of DC-DC converters operating in DCM has been investigated in this paper. The important control characteristics of the most relevant converters operating with $\mathrm{MC}$ have been presented, demonstrating that it is possible to use the converter filter inductance as control parameter to regulate output voltage or current.

The buck converter has been selected as case study to evaluate the possibilities of MC of DC-DC converters. The dynamic model of the MC DCM buck converter proves to be similar to that resulting from other control methods, as voltage-mode, current-programmed or frequency-sweep mode control. Since the converter operates in DCM, it keeps its first order behavior, exhibiting a main pole given by the filter capacitance and load resistance. The MC introduces a second pole defined by the effective inductance of the VI bias winding and by the addition of the output resistance of the current source used to drive the bias winding and the series resistance of the bias winding itself.

The obtained experimental results have proven the theoretical model of the MC buck converter. It has also been demonstrated how the converter can be closed-loop controlled with a simple lag-lead controller that can be designed based on conventional design methods. The experimental measurement of the converter loop gain and the load and input-voltage step responses are in full agreement with the closed-loop design of the converter.

As an additional conclusion, MC DC-DC converters can be used in other applications, such as in LED drivers, electric vehicle charging, DC motor control, PV converters, smartgrid converters, PFC converters, wireless power transfer, etc.
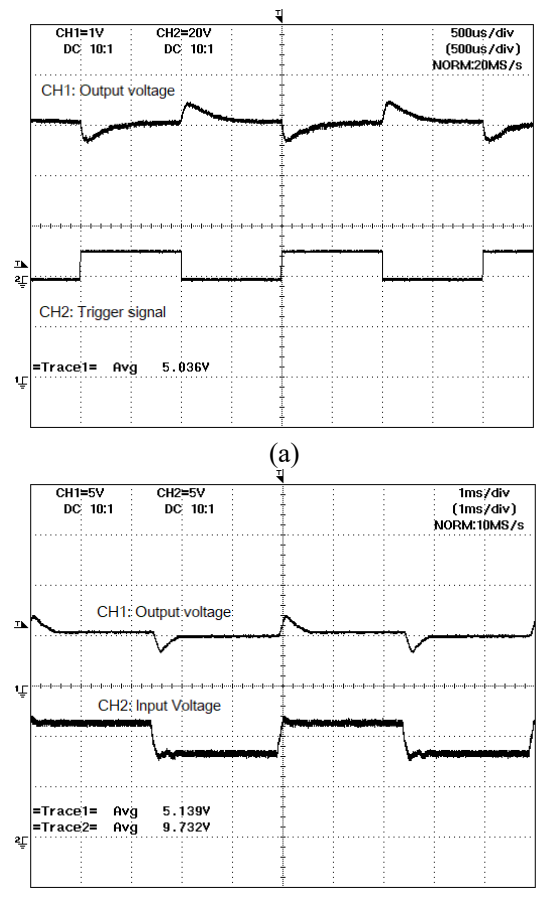

(b)

Fig. 16. Experimental closed-loop response of the magnetically controlled buck converter with a lag-lead compensator: (a) Output voltage transient for a load step change between $5 \Omega$ and $10 \Omega$, (b) Output voltage transient for an input voltage step between $8 \mathrm{~V}$ and $11 \mathrm{~V}$. $\mathrm{CH} 1, \mathrm{CH} 2$ and time scales are as labelled in the figures.
TABLE V. EXPERIMENTAL RESULTS: LOAD REGULATION FOR 10 V INPUT VOLTAGE

\begin{tabular}{|c|c|c|c|}
\hline $\begin{array}{c}\text { Output Current } \\
(\mathrm{A}), I_{o}\end{array}$ & $\begin{array}{c}\text { Output Voltage } \\
(\mathrm{V}), V_{o}\end{array}$ & $\begin{array}{c}\text { Control } \\
\text { Voltage }(\mathrm{V}), v_{c}\end{array}$ & $\begin{array}{c}\text { VI Bias } \\
\text { Current (A), } i_{b}\end{array}$ \\
\hline 1.15 & 5.01 & 1.10 & 0.38 \\
\hline 0.98 & 5.01 & 0.93 & 0.24 \\
\hline 0.83 & 5.02 & 0.87 & 0.17 \\
\hline 0.71 & 5.02 & 0.82 & 0.13 \\
\hline 0.62 & 5.02 & 0.79 & 0.09 \\
\hline 0.52 & 5.03 & 0.74 & 0.06 \\
\hline 0.48 & 5.03 & 0.73 & 0.04 \\
\hline
\end{tabular}

TABLE VI. EXPERIMENTAL RESULTS: LINE REGULATION FOR $5 \Omega$ LOAD RESISTANCE.

\begin{tabular}{|c|c|c|c|c|}
\hline $\begin{array}{c}\text { Input } \\
\text { Voltage } \\
(\mathrm{V}), V_{i}\end{array}$ & $\begin{array}{c}\text { Output } \\
\text { Voltage } \\
(\mathrm{V}), V_{o}\end{array}$ & $\begin{array}{c}\text { Output } \\
\text { Current } \\
(\mathrm{A}), I_{o}\end{array}$ & $\begin{array}{c}\text { Control } \\
\text { Voltage } \\
(\mathrm{V}), v_{c}\end{array}$ & $\begin{array}{c}\text { VI Bias } \\
\text { Current } \\
(\mathrm{A}), i_{b}\end{array}$ \\
\hline 8.5 & 4.83 & 1.00 & 2.86 & 0.85 \\
\hline 9.0 & 4.99 & 1.03 & 1.27 & 0.47 \\
\hline 9.5 & 5.00 & 1.04 & 1.04 & 0.35 \\
\hline 10.0 & 5.00 & 1.04 & 0.93 & 0.25 \\
\hline 10.5 & 5.01 & 1.04 & 0.90 & 0.21 \\
\hline 11.0 & 5.02 & 1.04 & 0.80 & 0.09 \\
\hline
\end{tabular}

\section{APPENDIX I}

DERIVATION OF CONSTANT $k_{l b}$ RELATING VI INDUCTANCE AND BIAS INDUCTION PERTURBATIONS

In this appendix the derivation of the constant $k_{l b}$ that relates the VI inductance and the bias induction perturbation will be presented for the case of the double E variable inductor.

As studied in [24], the main winding flux of the double-E variable inductor can be expressed as a function of the smallsignal reluctances as follows:

$$
\hat{\phi}\left(B_{b}\right)=\frac{N \hat{\imath}}{r_{t}\left(B_{b}\right)}
$$

where $B_{b}$ is the DC bias induction in the magnetic material, $\hat{\imath}$ is the small-signal current through the main winding, and $r_{t}$ is the total small-signal reluctance seen by the main flux, which can be expressed as:

$$
r_{t}\left(B_{b}\right)=r_{c}+r_{g c}+\frac{1}{2} r_{e}\left(B_{b}\right)+\frac{1}{2} r_{g e}
$$

$r_{c}$ being the central arm reluctance, $r_{g c}$ the central air gap reluctance, $r_{e}$ the outer arms reluctance, and $r_{g e}$ the outer arms air gap reluctance. These reluctances are defined as follows:

$$
\begin{gathered}
r_{c}=\frac{l_{c}}{\mu_{d}(0) A_{c}} \\
r_{g c}=\frac{l_{g c}}{\mu_{0} A_{c}} \\
r_{e}\left(B_{b}\right)=\frac{l_{e}}{\mu_{d}\left(B_{b}\right) A_{e}} \\
r_{g e}=\frac{l_{g e}}{\mu_{0} A_{e}}
\end{gathered}
$$

where $l_{c}, A_{c}$ and $l_{e}, A_{e}$ are the lengths and cross-sectional areas of the central and outer arms respectively, $l_{g c}$ and $l_{g e}$ are the central arm and outer arms air gap lengths respectively, $\mu_{0}$ is the permeability of free space, and $\mu_{d}$ is the differential permeability of the magnetic material, which can be expressed as a function of the bias induction using the Brauer's fitting [24], as follows 


$$
\mu_{d}\left(B_{b}\right)=\frac{1}{k_{1}\left(1+2 k_{2} B_{b}^{2}\right) e^{k_{2} B_{b}^{2}}+k_{3}}
$$

where $k_{1}, k_{2}, k_{3}$ are constants of the magnetic material.

Now, the main winding inductance can be derived from (I.1) as

$$
L\left(B_{b}\right)=\frac{N \hat{\phi}\left(B_{b}\right)}{\hat{\imath}}=\frac{N^{2}}{r_{t}\left(B_{b}\right)}
$$

Taking derivatives on (I.8):

$$
d L\left(B_{b}\right)=-\frac{N^{2}}{r_{t}^{2}\left(B_{b}\right)} \frac{d r_{t}\left(B_{b}\right)}{d B_{b}} d B_{b}
$$

Applying the Laplace transform on (I.9), the relationship between inductance and bias induction perturbation is obtained as desired:

$$
l(s)=k_{l b} B_{b}(s)
$$

where the constant $k_{l b}$ is defined as follows:

$$
k_{l b}=-\frac{N^{2}}{r_{t}^{2}\left(B_{b}\right)} \frac{d r_{t}\left(B_{b}\right)}{d B_{b}}
$$

In order to obtain an expression for $k_{l b}$ the derivative of the total reluctance is first obtained:

$$
\frac{d r_{t}\left(B_{b}\right)}{d B_{b}}=\frac{1}{2} \frac{d r_{e}\left(B_{b}\right)}{d B_{b}}=-\frac{l_{e}}{2 A_{e} \mu_{d}^{2}\left(B_{b}\right)} \frac{d \mu_{d}\left(B_{b}\right)}{d B_{b}}
$$

By deriving (I.7), substituting in (I.12), and then in (I.11), the constant $k_{l b}$ can be obtained as a function of the bias induction at a given operating point:

$$
k_{l b}=-\frac{N^{2}}{r_{t}^{2}\left(B_{b}\right)} \frac{l_{e}}{A_{e}} k_{1} k_{2} B_{b}\left[3+2 k_{2} B_{b}^{2}\right] e^{k_{2} B_{b}^{2}}
$$

In order to evaluate $k_{l b}$ at a given operating point it is necessary to obtain the value of the bias induction $B_{b}$ for a given dc bias current $I_{b}$. As analyzed in [24], the dc bias flux in the double-E structure is given by the following expression:

$$
\phi_{b}=\frac{N_{b} I_{b}}{\mathcal{R}_{e}+\mathcal{R}_{g e}}
$$

$\mathcal{R}_{e}$ and $\mathcal{R}_{g e}$ being the great-signal reluctances of the outer arms and outer arm air gap respectively:

$$
\begin{gathered}
\mathcal{R}_{e}=\frac{l_{e}}{\mu_{t}\left(B_{b}\right) A_{e}} \\
\mathcal{R}_{g e}=\frac{l_{g e}}{\mu_{0} A_{e}}
\end{gathered}
$$

where $\mu_{t}\left(B_{b}\right)$ is the total permeability of the magnetic material, which using the Brauer's fitting can be expressed as:

$$
\mu_{t}(B)=\frac{1}{k_{1} e^{k_{2} B^{2}}+k_{3}}
$$

Using (I.14)-(I.16), the following equation relating $B_{b}$ and $I_{b}$ is obtained:

$$
B_{b}-\frac{N_{b} I_{b}}{\frac{l_{e}}{\mu_{t}\left(B_{b}\right)}+\frac{l_{g e}}{\mu_{0}}}=0
$$

By solving (I.18) the value of the bias induction $B_{b}$ can be obtained for a given value of the bias winding current $I_{b}$. The obtained value of $B_{b}$ can then be used to calculate $k_{l b}$ using (I.13) for a determined operating point.

APPENDIX II.

DERIVATION OF THE H PARAMETERS OF TRANSISTOR BD139 FROM SPICE MODEL
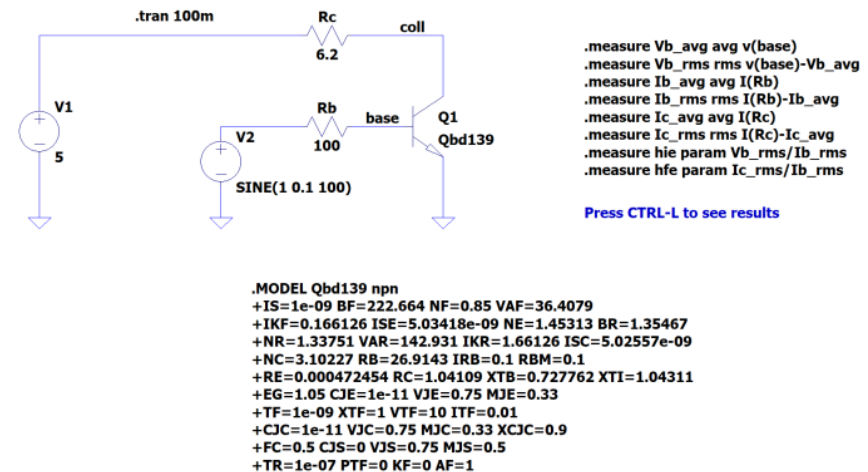

Fig. A.1. LTspice circuit used for obtaining $h_{i e}$ and $h_{f e}$ parameters of transistor BD139.
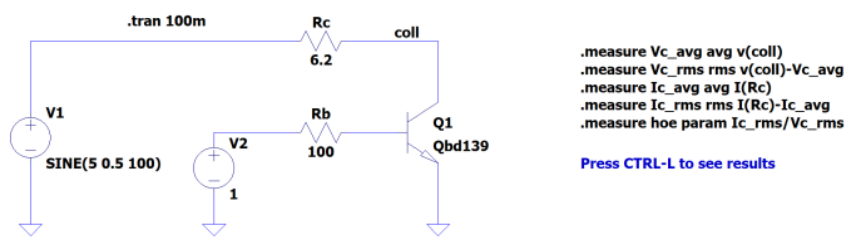

MODELL Qbd139 npn
$+\mathrm{IS}=1 \mathrm{e}-09 \mathrm{BF}=222.664 \mathrm{NF}=0.85 \mathrm{VAF}=36.4079$

$+\mathrm{IKF}=0.166126$ ISE $=5.03418 \mathrm{e}-09 \mathrm{NE}=1.45313 \mathrm{BR}=1.35467$ 作 $+\mathrm{RE}=0.000472454 \mathrm{RC}=1.04109 \times \mathrm{TB}=0.727762 \times \mathrm{TII}=1.04311$ $+E G=1.05$ CJE $=16-11$ VJE $=0.75 \mathrm{MJE}=0.33$ $+T F=1 \mathrm{e}-09 \times \mathrm{TFF}=1 \mathrm{VTF}=10 \mathrm{TTF}=0.01$ $+F C=0.5 C J S=0$ VJS $=0.75 \mathrm{MJS}=0.5$ $+\mathrm{T}=0.5 \mathrm{C}$ - $\mathrm{PS}=0 \mathrm{~V}=0 \mathrm{~S}=0.75 \mathrm{MJS}=0.5$
$+\mathrm{KF}=0 \mathrm{AF}=1$

Fig. A.2. LTspice circuit used for obtaining $h_{o e}$ parameter of transistor BD139.

\section{APPENDIX III}

WINPYTHON 3.7.7 SCRIPT FOR OBTAINING THE DYNAMIC MODEL OF THE LABORATORY PROTOTYPE

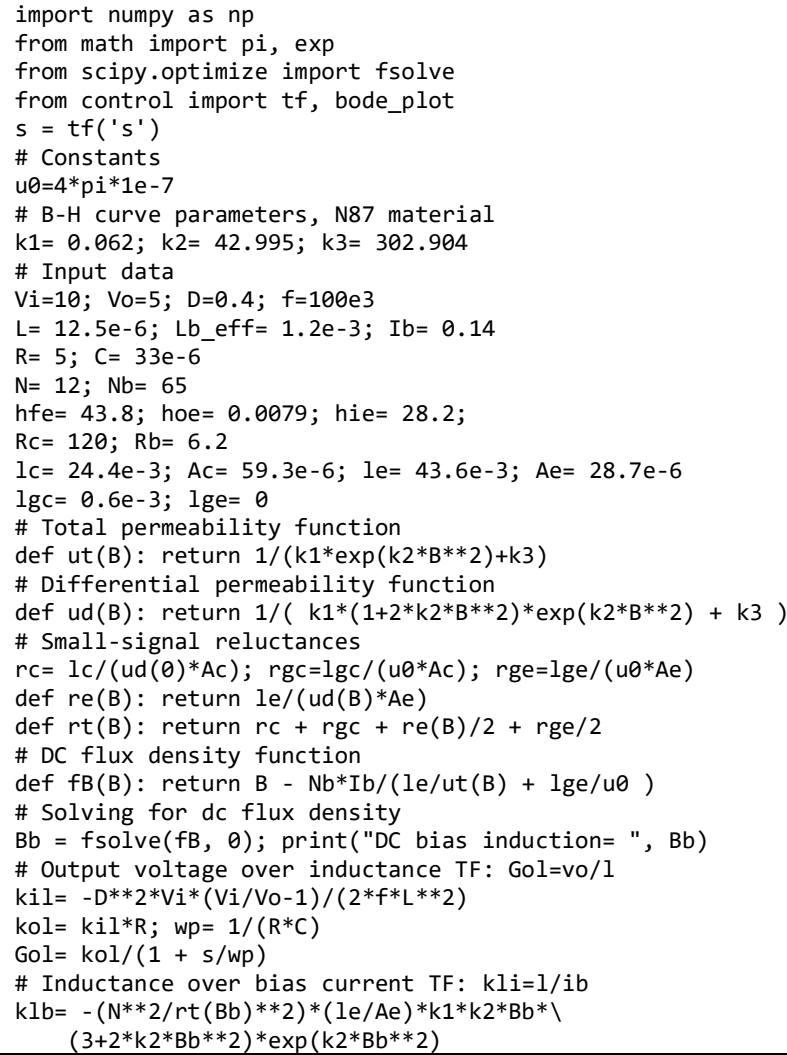




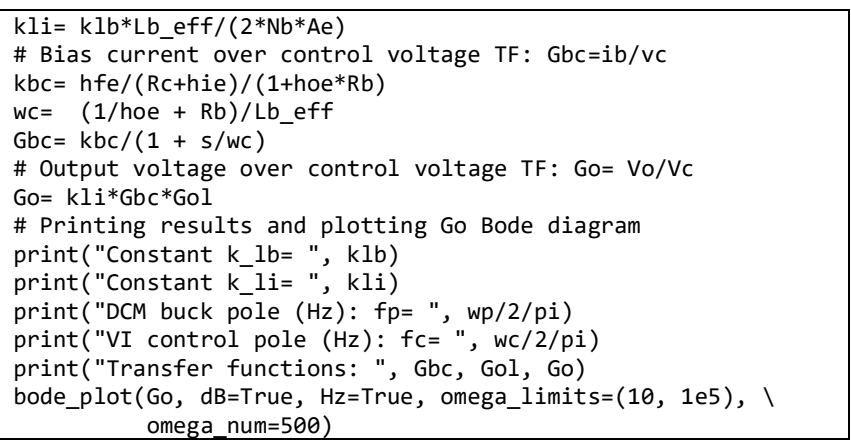

\section{REFERENCES}

[1] M. K. Kazimierczuk; Pulse Width Modulated DC-DC Power Converters. Wiley, 2008.

[2] A. S. Kislovski, "Quasi-linear controllable inductor," Proc. of the IEEE, vol. 75, No. 2, Feb. 1987, pp. 267-269.

[3] M. S. Perdigao, M. Menke, A. R. Seidel, R. A. Pinto, J. M. Alonso, "A review on variable inductors and variable transformers: Applications to lighting drivers," IEEE Trans. on Ind. App., Jan. 2016.

[4] M. Gulko, D. Medini and S. Ben-Yaakov, "Inductor-controlled current-sourcing resonant inverter and its application as a high pressure discharge lamp driver," Proc. of 1994 IEEE App. Power Electr. Conf. and Exp. - APEC'94, Orlando, FL, USA, 1994, pp. 434-440 vol.1.

[5] J. M. Alonso, M. A. Dalla Costa, M. Rico-Secades, J. Cardesín, J. Garcia, "Investigation of a New Control Strategy for Electronic Ballasts Based on Variable Inductor", IEEE Trans. on Ind. Electr., Vol. 55, N $\mathrm{N}^{\mathrm{o}} 1$, pp. 3-10, Jan. 2008.

[6] M. F. Menke, M. F. da Silva, A. R. Seidel, M. S. Perdigão and J. M. Alonso, "High power factor dimmable self-oscillating electronic ballast with variable inductor control," IEEE App. Power Electr. Conf. and Expo. (APEC), 2015, Charlotte, NC, 2015, pp. 3314-3321.

[7] M. S. Perdigao, J. M. Alonso, M. A. Dalla Costa, E. S. Saraiva, "Comparative Analysis and Experiments of Resonant Tanks for Magnetically Controlled Electronic Ballasts," Ind. Electr., IEEE Trans. on, vol.55, no.9, pp. 3201-3211, Sept. 2008.

[8] M. S. Perdigao, J. M. Alonso, M. A. Dalla Costa, E. S. Saraiva, "Using Magnetic Regulators for the Optimization of Universal Ballasts," IEEE Trans. on Power Electr., vol.23, no.6, pp. 3126-3134, Nov. 2008.

[9] U. Boeke, "Scalable fluorescent lamp driver using magnetic amplifiers," European Power Electr. Conf. and Expo. (EPE), pp. 1-10, 2005.

[10] J. M. Alonso, M. S. Perdigão, D. G. Vaquero, A. J. Calleja, E. S. Saraiva, "Analysis, Design, and Experimentation on ConstantFrequency DC-DC Resonant Converters With Magnetic Control," IEEE Trans. on Power Electr., vol. 27, no. 3, pp. 1369-1382, March 2012.

[11] Q. M. Luo, H. Yan, S. Chen and L. W. Zhou, "Interleaved high stepup zero-voltage-switching boost converter with variable inductor control," in IET Power Electr., vol. 7, no. 12, pp. 3083-3089, 122014.

[12] S. M. Ahsanuzzaman ; Timothy McRae ; Mor M. Peretz ; Aleksandar Prodić; "Low-volume buck converter with adaptive inductor core biasing," Proc. of IEEE Applied Power Electronics Conference and Exposition (APEC), pp. 335 - 339, 2012.
[13] Y. Wei, Q. Luo, J. M. Alonso and A. Mantooth, "A Magnetically Controlled Single-Stage AC-DC Converter," in IEEE Transactions on Power Electronics, vol. 35, no. 9, pp. 8872-8877, Sept. 2020.

[14] M. W. Beraki, J. P. F. Trovão, M. S. Perdigão and M. R. Dubois, "Variable Inductor Based Bidirectional DC-DC Converter for Electric Vehicles," in IEEE Trans. on Vehicular Tech., vol. 66, no. 10, pp. 8764-8772, Oct. 2017

[15] L. Zhang, W. G. Hurley and W. Wölfle, "A new approach to achieve maximum power point tracking for PV system with a variable inductor," The 2nd International Symposium on Power Electronics for Distributed Generation Systems, Hefei, 2010, pp. 948-952.

[16] C.-Y. Lim, J. H. Kim, Y. Jeong, D.-K Kim, H.-S. Youn, G.-W. Moon, "A high efficiency critical mode boost PFC using a variable inductor," 2016 IEEE 8th Int. Power Electr. and Motion Control Conf. (IPEMCECCE Asia), Hefei, 2016, pp. 2792-2797.

[17] Y. Wei, Q. Luo, J. M. Alonso and A. Mantooth, "A Magnetically Controlled Single-Stage AC-DC Converter," in IEEE Transactions on Power Electronics, vol. 35, no. 9, pp. 8872-8877, Sept. 2020.

[18] R. A. Pinto, J. M. Alonso, M. S. Perdigão, M. F. da Silva and R. N. do Prado, "A New Technique to Equalize Branch Currents in Multiarray LED Lamps Based on Variable Inductors," in IEEE Trans. on Industry Applications, vol. 52, no. 1, pp. 521-530, Jan.-Feb. 2016.

[19] Y. Hu, L. Huber and M. M. Jovanović, "Single-Stage, Universal-Input AC/DC LED Driver with Current-Controlled Variable PFC Boos Inductor," in IEEE Transactions on Power Electronics, vol. 27, no. 3, pp. 1579-1588, March 2012.

[20] J. M. Alonso, M. Perdigao, M. A. Dalla Costa, G. Martínez and R. Osorio, "Analysis and Experiments on a Single-Inductor Half-Bridge LED Driver with Magnetic Control," IEEE Trans. on Power Electronics, vol. 32, no. 12, 9179-9190.

[21] S. Saeed and J. Garcia, "Extended Operational Range of Dual-ActiveBridge Converters by using Variable Magnetic Devices," 2019 IEEE Applied Power Electronics Conference and Exposition (APEC), Anaheim, CA, USA, 2019, pp. 1629-1634.

[22] Y. Wei, Q. Luo, X. Du, N. Altin, A. Nasiri and J. M. Alonso, "A Dual Half-Bridge LLC Resonant Converter With Magnetic Control for Battery Charger Application," in IEEE Transactions on Power Electronics, vol. 35, no. 2, pp. 2196-2207, Feb. 2020.

[23] Y. Wei, Q. Luo, S. Chen, Q. He and L. Zhou, "A High Efficiency Single Stage Bi-directional Battery Charger with Magnetic Control," 2018 IEEE Int. Power Electronics and Application Conf. and Exp. (PEAC), Shenzhen, 2018, pp. 1-6.

[24] J. M. Alonso, M. Perdigão, M. A. Dalla Costa, S. Zhang and Y. Wang, "Variable inductor modeling revisited: The analytical approach," 2017 IEEE Energy Conv. Congr. and Exp. (ECCE), Cincinnati, OH, 2017, pp. 895-902.

[25] J. M. Alonso, G. Martínez, M. Perdigão, M. R. Cosetin and R. N. do Prado, "A Systematic Approach to Modeling Complex Magnetic Devices Using SPICE: Application to Variable Inductors," in IEEE Trans. on Power Electr., vol. 31, no. 11, pp. 7735-7746, Nov. 2016.

[26] J. M. Alonso, M. Perdigao, G. Z. Abdelmessih, M. A. Dalla Costa, Y. Wang, "SPICE Modeling of Variable Inductors and its Application to Single Inductor LED Driver Design," in IEEE Trans. on Ind. Electr., vol. 64, No. 7, 5894-5903, Jul. 2017.

[27] J. M. Alonso, M. Perdigão, M. A. Dalla Costa, S. Zhang, Y. Wang; "Analysis and experimentation of the quad-U variable inductor for power electronics applications," IET Power Electronics, 11 (14), 23302337, 2019. 